\title{
Patient-Made Videos as a Tool of Self-Observation Enhancing Self- Reflection in Psychotherapy
}

\author{
Description of the Method and a Clinical Case
}

\author{
Tarja Koffert $^{1} \cdot$ Sinikka Luutonen ${ }^{2,3}(1) \cdot$ Päivi M. Niemi ${ }^{4} \cdot$ Juhani Tiuraniemi $^{5} \cdot$ Elisa Nordström $^{6} \cdot$ Matti Keinänen $^{2}$. \\ Jarmo Hietala ${ }^{2,3}$
}

Published online: 15 April 2019

(c) The Author(s) 2019

\begin{abstract}
Photographs have been used in psychotherapy from the late 1970s, but patient-made videos have not been used directly as an integral part in individual psychotherapeutic treatment. We now propose a new approach, VideoTalk, using visual material as an aid in the psychotherapy process with a schema therapy framework as an example. VideoTalk builds on life-review method, providing information about the patient's social relations, coping skills, affect/emotion regulation and schemas. This information is used as a platform for focused patient-made videos, i.e. self-talk at home in a typical problematic situation for the patient. The VideoTalk method enables documentation of the expression of mind states and dysfunctional schemas in a natural environment and related to an everyday emotional context. Subsequently, this video material is watched step by step together with the therapist. In this report, we describe the flow and functionality of the VideoTalk method through the case of a 24-year-old female patient suffering from depression and social phobia. The self-mirroring from the video facilitates self-observations of the patient's own facial expressions, voice and body posture. We hypothesize that this new information gradually changes emotional processing, leads to better self-awareness and strengthens more functional schemas.
\end{abstract}

Keywords Psychotherapy $\cdot$ Video $\cdot$ Self-reflection $\cdot$ Emotional activation

Sinikka Luutonen

sinikka.luutonen@utu.fi

1 Private Psychotherapy Service, Käsityöläiskatu 14D, 20100 Turku, Finland

2 Department of Psychiatry, University of Turku, Turku, Finland

3 Department of Psychiatry, Turku University Hospital, PO Box 52, 20521 Turku, Finland

4 Department of Teacher Education, University of Turku, Turku, Finland

5 Private Psychotherapy Service, Peltokatu 25, 20540 Turku, Finland

6 Private Psychotherapy Service, Linnankatu 27C, 20100 Turku, Finland

\section{Introduction}

There is abundant evidence on the effectiveness of cognitive behavior psychotherapy (CBT) in several mental disorders; especially in depression and anxiety disorders (Hofman et al. 2012; Watts et al. 2015). However, many limitations and challenges have been acknowledged such as residual symptoms and relapses after successful CBT (Leichsenring and Steinert 2017). The results of successful psychotherapy may not be generalized to patients' everyday contexts. In addition, learning new skills including those of emotional regulation requires several repetitions in order to become stabile and automatic. Patient's motivation to and active collaboration in therapy (e.g. doing homework between the sessions; Conklin and Strunk 2015) as well a good trustworthy psychotherapeutic alliance are utterly important for the effectiveness of the psychotherapy (Flückiger et al. 2012). Especially patients having unmet needs and disappointments in their close relationships, lack of self-worth and feelings 
of self-shame may find it difficult to reach and disclose their most painful self-experiences in face-to-face contact with another person. In this article, we describe VideoTalk method developed to meet these challenges, give a case illustration, and report preliminary findings on VideoTalk process and psychotherapeutic change.

\section{Rationale}

\section{Emotions in the Forefront of Cognitive Psychotherapy}

Cognitive psychotherapy has traditionally focused on expectations, attributions and beliefs, while less attention has been given to emotions. However, since early 1990s the role of emotions has also been acknowledged by proponents of the cognitive approach (Safran and Muran 2000) emphasizing the importance of emotion activation for a deeper change in psychotherapy. Teasdale and Barnard (1993) have presented a comprehensive model, Interacting Cognitive Subsystems, which recognizes two levels of meaning, a propositional level and an implicational level. The propositional level is linguistically based and propositional meanings may be dealt with traditional cognitive techniques. The implicational level, however, can be seen as affect-laden schematic models of experience. Teasdale and Barnard suggest that a high-level change in psychotherapy cannot happen without a change on the implicational level with emotional content. Consequently, the emerging "third wave" in cognitive therapy has contributed to development of mindfulness-based cognitive therapy, dialectical behavior therapy, acceptance and commitment therapy and metacognitive therapy and has emphasized issues of emotions, decentering, relationships and psychological flexibility processes. These approaches and interventions are nowadays a part of CBT tradition since growing evidence suggests they are helpful (Hayes and Hofmann 2017; Norton and Paulus 2016).

\section{Use of Visual Material in Psychotherapy}

It has been found that using photographs helps talking and reveals emotions rapidly in psychotherapy (Loewenthal 2013). The photograph, however, is static and does not necessarily catch all the important elements of an experience. Compared with photographs video material conveys more information including movement and sound. Videos give multi-modal information through various senses: the patient can see his/her changing facial expressions and bodily movements, hear his/her voice, and perhaps feel in his/her body the same tensions that can be seen on the video (Steele et al. 2014). Neuroimaging evidence suggests that in comparison with static facial expressions, dynamic facial stimuli evoke increased activation in brain regions associated with emotional processing (Arsalidou et al. 2011).

So far, using visual, especially video material, has not been common in psychotherapeutic work. The studies on using video in psychotherapy have concentrated on two subjects: treating social phobia and improving parent-child interaction. In the treatment of social phobia, patients are videotaped in a performance situation, e.g. making a speech (Orr and Moscovitch 2014; Warnock-Parkes et al. 2017). They are asked to predict how they will appear in the video and they are instructed to watch the video as if through the eyes of an objective observer. In the interventions for improving parenting (Kennedy et al. 2017), typical way of using the video has been to videotape parent-child interaction, to edit the video, and to watch it together with the parent, letting the parent make observations. Afterwards, the parent's observations, thoughts and emotions evoked when watching the video are discussed together with the therapist.

\section{Sharing and Reflecting Video Feedback with Psychotherapist}

By using visual material, nuanced aspects of non-verbal communication can be utilized (Steele et al. 2014) and implicational meanings be reached to a greater extent in psychotherapeutic encounters. Sharing biographical photographs, videos and their emotional content may also facilitate the building of a therapeutic relationship (Loewenthal 2013; Steele et al. 2014). Watching a video together with a psychotherapist gives the patient a good opportunity to see him/herself from outside with someone validating his/ her experience. Thus, working with videos may accelerate the activation of emotions in psychotherapy and especially using home-made videos makes it possible to bring a difficult situation felt at home to a psychotherapy session in a genuine form. This apparently builds a basis for enhancing self-awareness and self-reflection. Since video feedback is, however, outspoken, objective and unavoidable, it may also be a harsh and utterly intensive intervention urging the availability of validation and support from the psychotherapist in order to facilitate patient's emotion awareness and selfreflection instead of avoidance.

The central phenomenon in viewing and sharing videos with a facilitator or therapist is decentering: creating space for experiencing one's own emotions and inner actions. Video provides a certain degree of distancing. When watching video, there can be some objective monitoring instead of subjective monitoring; i.e. patients learn to observe their experiences from "outside". Decentering seems to be the principal mechanism that correlates with the success of psychotherapeutic treatment of various disorders (HayesSkelton and Graham 2013; Segal et al. 2019). 
In all, video-based interventions may enhance emotional awareness, self-reflection and adaptive coping. Although using videos is likely to accelerate desired change processes, to date there is no research that has clearly investigated the added value of using video in the intervention as compared with delivering the same intervention without using video.

\section{VideoTalk: Home-Made Videos Used in Psychotherapy}

To meet these challenges VideoTalk method using videos made by patients at home and shared in psychotherapy sessions was developed together with patients. To our knowledge, there is no research on psychotherapy using patient-made videos. One reason might be that convenient equipment (smart phones, tablet computers) to make videos at home have not been available until recent years. Nowadays making "selfies" and videotapes is common in people's everyday life. In the following we describe the VideoTalk working methods and give an illustrative case example. The purpose of this study is to describe how the patient's emotion recognition, emotion awareness and expression of emotions may come out during the VideoTalk process. Secondly, we detect how the patient's self-awareness and self-reflection may emerge: are there self-observations and responses indicating mismatch between expectations and reality, and what are the indications of the patient's ability for decentering and self-reflection? Thirdly, we aim to identify possible changes in patient's coping, activity in everyday life and feeling of self-agency. Fourthly, along the illustration of the whole VideoTalk process we explore the therapist's contribution to and the impact of therapeutic alliance on this process.

\section{Development of the VideoTalk Method}

In the VideoTalk, we use patient-made videos as a tool for self-observation. Visual material is used to bring self as a focus of patient's observation, to activate emotions, to aid self-reflection, and to help the patient to change his/her problematic compensatory strategies, which have developed as a coping response to unmet emotional core needs. The homemade visual material builds a bridge between therapy sessions and the patient's daily life at home and it helps to make the psychological change more concrete. The patient's role is central in carrying out the therapy. Between the sessions, the patient works independently at home taking photographs and making videos of him/herself. The patients use their mobile phones or computers to produce the visual material of themselves. Further, the patient makes daily notes of matters promoting his/her well-being. The aim is to strengthen new, more adaptive ways relating to himself/herself and to find what kind of advantages this brings to the daily life.
The role of the therapist is active, guiding, and emotionally sharing. The therapeutic relationship builds on shared experiences of work done together. In clinical work, we have used the VideoTalk method in treating young adults with depression and/or anxiety disorders who are "stuck", repeating dysfunctional coping strategies.

It is possible to combine the VideoTalk method or its elements with various psychotherapy orientations. We have used the schema therapy approach developed by Young (1990) as a theoretical framework for the VideoTalk method because it comprehensively addresses essential elements of psychological development and psychotherapeutic change (e.g. early emotional and cognitive development, adult coping).

Difficult emotions related to unmet emotional needs and their meaning and presence in adult everyday contexts are essential elements of schema therapy. Schema therapy was initially developed for the treatment of personality disorders (Bamelis et al. 2014), but it has been promising also in treating depression (Carter et al. 2013; Renner et al. 2016). It focuses on early maladaptive schemas, which can be defined as pervasive life patterns influencing cognitions, emotions, memories, and bodily sensations. Maladaptive schemas develop in childhood or in adolescence, when core emotional needs of an individual are not met. Maladaptive schemas are active also in adulthood causing considerable suffering. The changing moment-to-moment emotional states and coping responses are called modes which have developed in childhood but which have still impact in later life. Young (1990) divided modes into four categories: Child Modes, Dysfunctional Coping Modes, Dysfunctional Parent Modes and Healthy Adult Mode. Child modes include Vulnerable, Angry, and Impulsive/Undisciplined Child. When these modes are activated a patient experiences difficult, painful emotions whereas the fourth mode "Happy Child" is characterized by positive feelings and absence of activated maladaptive schema. Dysfunctional Parent Modes (i.e. Punitive/Critical Parent and Demanding Parent) are internalizations of parent figures in a patient's early life and include the most negative characteristics of them. Maladaptive Coping Modes are compensatory strategies through which the child has tried to adapt to damaging childhood experiences. For example, some children surrender to their schemas (Compliant Surrender); some find ways to block out or avoid pain (Detached Protector) while others fight back or overcompensate (Overcompensator). Often maladaptive coping modes are triggered by challenging life situations a person is oversensitive to and they lead a person to overreact to these situations, or to act in ways that end up hurting him/ her. On the contrary, Healthy Adult Mode is the healthy adult part which helps a person to meet the child's basic emotional needs and to work with the other modes. In schema therapy, patients are encouraged to get acquainted with their modes and to get back in touch with their core needs and feelings. 
The goal is to strengthen patients' Healthy Adult Mode and weaken Maladaptive Coping Modes, to break schema-driven life patterns and eventually to get their core emotional needs met in everyday life.

Schema therapy consists of two parts: in the first part, the therapist helps the patient to identify his/her maladaptive schemas, to understand their origin in childhood, and to link them with present problems. In the second part of schema therapy, the therapist uses cognitive, experiential, behavioral and interpersonal techniques to help the patient to replace maladaptive schemas with more adaptive ones. When using the VideoTalk in schema therapy context, the first part of therapy is intensified by using the patient's album photos to build a life-review and by working with face photos taken by the patient during the therapy; in the second part of therapy, home-made videos are used.

\section{The Process and Working Methods of the VideoTalk}

In the VideoTalk, there are three phases: the life-review phase, the face photo phase, and the video phase. The structure of the VideoTalk method and goals related to different phases are shown in Table 1.

\section{Using Album Photos to Build a Life-Review}

The patient brings to the therapy session photographs from his/her childhood, school years, and present days, which he/ she thinks describe important moments in his/her life. The patient is asked to talk freely about the photographs and tell stories associated with them. The therapist sits by the patient asking questions about the photographs. The photographs are attached to a large sheet of paper. The patient's observations on the photographs and his/her thoughts and meanings associated with them are written below each picture. This visual life review is on view in every therapy session and new observations and notes are added to it if needed. As a result, the paper contains much information on the patient's life, social relations, coping skills, environment, modes of thinking etc. On the basis of the life-review work, the patient's problematic pervasive life patterns (maladaptive schemas) are summarized together. Schemas regarded by the patient as most problematic ones will be the focus of future psychotherapeutic work. Our experience has been that building an adequate life-review takes three sessions.

\section{Using Face Photographs to Get Acquainted with Emotions}

The patient is asked to take face photographs of himself/ herself in different situations of everyday life and bring these photos to the therapy session. Emotions shown on the face differ according to what has happened and with whom the patients has been in contact. We hypothesize that expressing different emotions becomes more acceptable because the patient knows how he/she looks in different emotion-evoking situations. When the patient sees his/her own sad face in the photograph, he/she may realize his/her own needs and accept them, and be more compassionate towards himself/herself.

Further, the patient has the opportunity to see the effect of early pervasive life patterns (maladaptive schemas) in different situations and relationships. He/she gets new information on his/her way of social interaction and he/she becomes more conscious of how certain people influence him/her. He/ she can also compare his/her inner experience of himself/ herself with the impression he/she gets when looking at him/ herself in the photograph.

\section{Using Home-Made Videos to Develop Adaptive Ways of Relating to Self and Others}

The patient is asked to make a video of himself/herself when he/she is alone at home. On the video, the patient is asked to talk on a given theme, e.g. "an incident that has influenced my way of thinking". The length of the video is not determined beforehand. The video is watched together with the therapist in the following session; the patient may also have watched the video beforehand by himself/herself. Watching the video with the therapist is done step by step in order to give the patient more time and to make it easier for him/her to approach emotions activated by the multi-sensual information received through the video. The patient is asked to verbalize the emotional experience of the present moment and tell about his/her observations of himself/herself on the video. The therapist presents his/her observations, comments and questions. The therapist aims at showing the connection between the patient's observations and the problematic life patterns (maladaptive schemas) found in the life-review phase, and encourages the patient to express his/her emotions and needs.

The VideoTalk works like a process. When the video film has been shared with the therapist, the patient is given a new homework assignment with the instruction "Make a new video focusing on what you have learnt from your observations of yourself on the video and sharing the video with the therapist". The purpose of this new video is to strengthen the more adaptive ways of relating to oneself and others. The new video is watched and discussed with the therapist in the following session focusing on what it means to the patient if he/she relates to himself/herself in the newly learnt way compared with the old one. Then, a new topic for the next video is given. We hypothesize that using homemade videos activates emotions, enhances self-reflection, and helps develop more adaptive ways of relating to other 


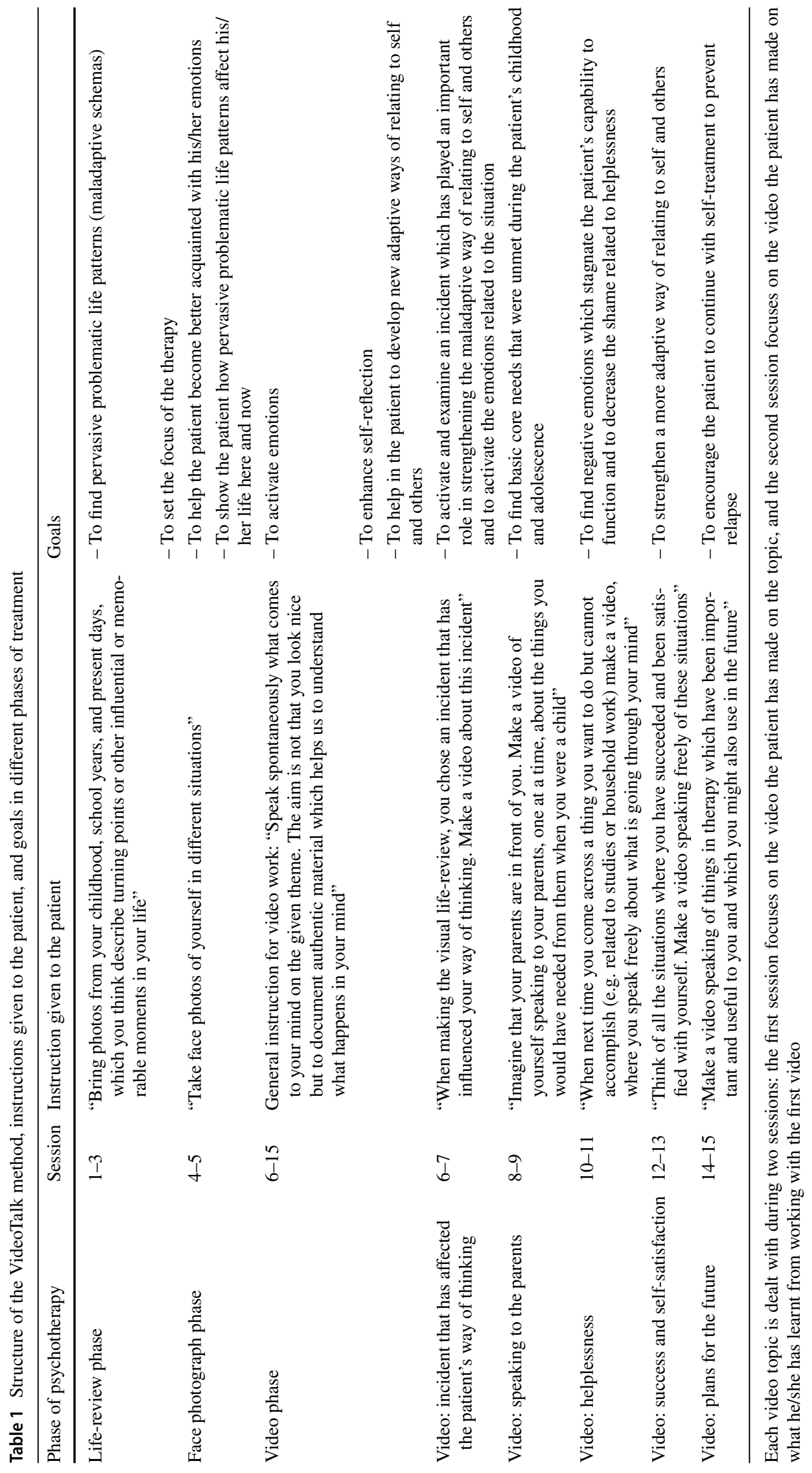


people instead of reacting according to old problematic life patterns (maladaptive schemas).

In the VideoTalk, we use five different videos topics: incident that has influenced the patient's way of thinking (to examine an incident that has strengthened the patient's problematic way of relating to himself/herself and others), speaking to the parents (to find basic unmet needs), helplessness (to find negative emotions that stagnate the patient's function ability), success and self-satisfaction (to strengthen a more adaptive way of relating to oneself), and plans for the future (to prevent relapse). Each topic is dealt with during two sessions: the first session focuses on the video the patient has made on the topic, and the second session focuses on the video the patient has made on what he/she has learnt from working with the first video. Because the patient owns all the visual material produced during the therapy, he/she may also use them after the therapy in order to find support in difficult life situations.

\section{Descriptive Case Presentation}

We shall describe using of the VideoTalk method in the schema therapy process of a 23-year-old woman. The psychotherapist was one of the authors (TK). She is a cognitive psychotherapist specialized in schema therapy. "Anna" was a student living with her boyfriend. She suffered from major depression and social phobia causing isolation. Attending lectures at the university had been impossible, and even going outside home had been difficult. Besides her parents and boyfriend, she had no contacts with other people. The Social and Occupational Functioning Assessment Scale (SOFAS; American Psychiatric Association 1994) score assessed by the therapist at the beginning of the therapy was 50 indicating a severely impaired functional ability. Anna's father had a demanding and dominating character. In Anna's childhood, he forcefully intruded into her life. Anna would have hoped for support from her mother, when depressed by her father. Anna's mother was submissive and withdrawn and Anna described her relation to her mother as distant. However, Anna felt that her childhood had been happy. Anna's symptoms began in a mathematics lesson when she was 15 years old. She was writing on the blackboard in front of her class, when a classmate asked her to write figures more clearly. Anna responded angrily, and after that she felt she was being bullied. She believed that if she had not shown her angry feelings, she could have avoided her later difficulties.

\section{Setting the Focus}

The visual life review showed the turning points in Anna's life and also the skills to cope with problems, social relations, ways of thinking at different age periods, as well as protective resources in her life. Anna found that at the age of 15 , her social behavior changed. She became more withdrawn at home and stayed in her room with her computer. She paid attention to other people's reactions more than earlier and tried to change her behavior to please others. It was forbidden to express anger. When she was angry she detached herself from the emotion by playing with her computer (maladaptive coping mode of Detached Protector).

When working with the life review, Anna named her life's main themes: the worthlessness of her own thoughts, prohibition to express anger, and a feeling of being different from others. She used to put the needs and wishes of others before her own and she usually tried to adapt her behavior according to others. The inability to express emotions and the tendency to sacrifice herself for others often led Anna to "stuck" situations in her life. The treatment was focused on these themes (maladaptive schemas of isolation and subjugation).

\section{Getting Acquainted with Emotions}

A new perspective on herself was opened to Anna by taking and looking at the face photographs. She noticed that her way of showing her emotions was very controlled. This was a new observation to her, which she found by herself when looking at the photos. She thought that she looked withdrawn. This discovery helped her to understand why people had difficulties in approaching her. She thought that her fear could not be observed in the photos. This observation completely astonished her. In all, she thought that her emotions showed up surprisingly weakly on her face, including also joy and curiosity. The most important observation was that when she did not look at others, she lost the contact with them and withdrew from them (Detached Protector Mode). Decentering helped her to find new views on herself. She had always found it difficult to express anger. She thought that her anger was turned inwards, as well as the feeling of being worried. She learnt that the maladaptive schemas of isolation and subjugation found in the life-review work strongly affected her present life.

The examination of her own emotions from face photos taught Anna that the expression of emotions made her face more interesting. Her understanding of the interaction between herself and others increased. She realized that emotions express important issues. Even negative emotions became more acceptable. Anna connected her need to control her emotions with her demanding father and with the distant relation to her mother.

Along with self-reflection with photographs, Anna's appearance became more relaxed and she began to wear more colorful clothes. She started attending lectures at the university and she began to work at the market place where 
she has a lot of contacts with other people. She also began to express even anger at home, and was able to read a paper in class without being anxious. Discussion with people became easier and she even dared to disagree.

\section{Learning New Ways to Relate to Self and Others}

\section{Video: "Incident that has influenced my way of thinking"}

Anna made a video at home about the incident in the mathematics class, when she felt she was being teased and responded to the teaser. She stated on the videotape: "That was a mistake, I should not have opened my mouth". She said she had noticed an astonished expression on the teaser's face. She thought that showing her anger in public had made her unpopular and bullied by peers at school. On the video, Anna heard her own hypothesis of the cause, why her life began to change. She had felt her behavior to be wrong and after that she had avoided expressing her anger. This had led to social isolation and narrowing of her life and it was difficult for Anna to trust people and she believed herself to be different from others. These observations were examined in relation to the life-review. Anna's life events could be seen on the visual lifeline from the distance which helped the therapist to show how this event has affected Anna's thinking of herself and changed her life. Now she got an insight into how this sporadic incident had influenced her way of interpreting issues, and how much this past incident influenced her in several situations even now. Anna connected her way of observing things with the themes found in the visual lifereview work. After this notion, Anna became sad because she felt that she had lost a lot by accepting the behavior of the school mates. Anna began to feel empathy towards herself. She understood that she had neglected herself and her own needs for a long time. The need to withdraw from emotions and other people (Detached Protector Mode) was questioned.

\section{Video: Speaking to the Parents}

Anna talked on the tape as if her father were sitting opposite her. She began like this: "Father, I am angry with you, because you have been over-protective my whole childhood. You have given orders and you have not trusted that I'll manage". She continued talking to her mother: "Mother, why did you not object when father scolded me. I have been feeling worthless. Why did you not say anything?" Talking on the video as if her parents were present revealed issues, which Anna would have liked to express in the past. The experiential exercise showed her loneliness and lack of social support. Anna learnt to understand that she must have put aside her own opinions and emotions connected with her parents. She had not been able to express her emotions of anger and disappointment. When listening and watching the video with the therapist, she could strongly feel both anger and sorrow (Angry Child Mode and Vulnerable Child Mode). She had an opportunity to talk about emotions that earlier had to be put aside as a consequence of missing emotional sharing with her parents. She could verbalize the core needs and share with the therapist her sadness and anger knowing that it is acceptable.

\section{Video: Helplessness}

Anna chose to work with helplessness related to a university course she attended where she had to make a speech and take part in group discussions. She was afraid of being seen as untalented and stupid compared with other students. She talked of her deficiencies all through the video (Demanding Parent Mode). After making the tape Anna watched it together with the therapist and talked about her observations. She was able to see her problems with studies in a new, more adaptive perspective (Healthy Adult Mode). On the second video Anna made after having shared the first one with the therapist, she said that she was surprised when she saw herself on the first video. She could not understand how miserable she looked. She stated that she was locked and withdrawn. She noticed the mismatch between the demands of the situation and what she saw on the video and asked: "How on earth can I look so miserable and uncertain?" and continued, "Nothing in my life is so wretched that I should be so stressed. Could it be so difficult to express my thoughts to other students?"

On the new video, she spoke to herself comfortingly and assured herself that there is no such misery at all. She noticed the discrepancy between the force of her emotions and the level of demands of the situation. She understood that she overreacted to the situation and underestimated her own capability. Only after the multi-sensual information that she got from the video, could she understand how the experience of helplessness influences her. She could combine the video information with her subjective experience. After the integration of these two, the situation appeared in a new light.

\section{Video: Success and Self-Satisfaction}

It was an important experience for Anna to hear herself talking in a constructive way to herself, saying aloud something accepting, appreciating, and meaningful. Anna spoke on the homemade videotape to herself and asked: "Why could I not be satisfied with myself like this?" She stated to herself that she will manage. "I can be different from others and still good enough." She added that it did not matter, if she could not say anything to her peers in a group situation. Talking on the video brought together central issues important to Anna's 
psychic well-being and her ability to take care of herself. Her own talk about the positive sides of herself seemed to be much more convincing than any words of the therapist.

Anna's therapy was one of our first therapies with the VideoTalk method, and it did not contain the Plans for the future video. After the therapy, Anna phoned the therapist telling about a difficult incident and fear of renewal of depressive symptoms. The therapist told Anna to make a video about the incident, which Anna did, and the situation resolved. This gave us the idea of the Plans for the future video assignment, which was later added to the VideoTalk method to encourage the patient to use newly learnt skills in daily life and to prevent relapse.

Shortly after the therapy, Anna completed the training required in her studies. It was easier for her to express her thoughts and needs. She could even oppose her father. She made new friends with whom she occasionally went out. She was not satisfied with her relationship with her boyfriend whom she found dominating. During the therapy, she got the courage to end the relationship. Anna experienced that she was able to influence her life and well-being. SOFAS (American Psychiatric Association 1994) score assessed by the therapist at the end of the therapy was 80 indicating a nearly normal functional ability.

\section{Discussion}

In Anna's case, the life-review phase rapidly activated problematic pervasive life patterns (maladaptive schemas) and working with face photos made emotions more acceptable. Working with videos activated emotions, enhanced selfreflection, and helped to develop more adaptive ways to relate to self and others.

The activation, recognition, and expression of anger and sorrow were central in Anna's psychotherapy. These emotions could be seen in some of the videos, and as a result of watching the video with the therapist, the emotions were intensified; on the other hand it was possible for Anna to feel compassion towards herself. In her life, Anna had escaped from painful emotions and isolated herself from daily routines, which lead to further worsening of her functional ability. It was important for Anna to reach the anger and sorrow behind the withdrawal behavior, and to see how she criticized herself in a ruthless way. Through experiencing hidden emotions of anger and sorrow, Anna found her unmet needs of love and nurture. Throughout the therapy, her capability of taking care of herself grew stronger.

In the VideoTalk method, the information from various senses is central. When working with face photos, Anna became aware of the mismatch between her own ideas and what she saw in the photos. This mismatch helped her to understand her problems at schema level. When Anna made observations by herself and heard them on the tape it was easier for her to believe that they are true. Watching a video together with a psychotherapist helped her in the decentering process made it possible to see herself from outside with a person validating her experience, which promoted selfreflection. Anna's daily life was changed during and after psychotherapy. She became socially, academically and professionally more active, and she ended her dissatisfying relationship with her boyfriend. She felt she was capable of increasing her own well-being.

The therapeutic relationship was equal, both partners being in the role of an expert. Using patient-made visual material stressed Anna's own responsibility and agency in the therapy. The life-review phase rapidly produced knowledge of Anna's life. It was easy for the therapist to enter her world because of the abundant visual documentation. Working with patient-made visual material helped to keep the sessions focused.

The usefulness of the VideoTalk method needs to be tested in controlled study designs. Further, it is unclear, which phases/videos are the most important for psychotherapeutic change. So far, the VideoTalk method has been used for young patients with mood and/or anxiety disorders who are familiar with using videos. Our clinical experience has been that most patients are willing to make videos of themselves. It is possible that socially anxious patients consider it difficult to videotape themselves and bring the video to the session. However, in our method, the patients are not given a performance task to be videotaped but they make the video at home expressing their thoughts and emotions on the theme agreed in the previous session. The possibility of watching the video first alone at home may decrease the anxiety and shame related to letting the therapist see the video. Further, videotaping is repeated several times, giving the patients time to get used to the method. It is also possible that some patients make the videos on a superficial level and avoid speaking about painful experiences. This kind of patients probably find it also difficult to talk about difficult experiences in face-to-face contact, and it could be thought that speaking alone at home on the videotape about painful life-events might be easier because the patient is speaking to himself/herself in the first place, and only secondly to the therapist. Anna was ready for video work and for her, a 15 session therapy was long enough while some patients may need a longer time to reach painful experiences. Using videos may accelerate the therapeutic change and reduce the shame often connected with psychic suffering.

We have used the VideoTalk in the context of schema therapy. We think that working with home-made videos could be combined with various psychotherapy orientations to facilitate self-observation and self-reflection and to activate emotions, all of which are central elements in most psychotherapy orientations. 
Acknowledgements Open access funding provided by University of Turku (UTU) including Turku University Central Hospital.

Funding This work was supported by the Irma Karila Fund and the Finnish Psychiatric Association.

Open Access This article is distributed under the terms of the Creative Commons Attribution 4.0 International License (http://creativeco mmons.org/licenses/by/4.0/), which permits unrestricted use, distribution, and reproduction in any medium, provided you give appropriate credit to the original author(s) and the source, provide a link to the Creative Commons license, and indicate if changes were made.

\section{References}

American Psychiatric Association. (1994). Diagnostic and statistical manual of mental disorders (4th ed). Washington, DC: American Psychiatric Association.

Arsalidou, M., Morris, D., \& Taylor, M. (2011). Converging evidence for the advantage of dynamic facial expressions. Brain Topography, 24(2), 149-163.

Bamelis, L., Evers, S. M., Spinhoven, P., \& Arntz, A. (2014). Results of a multicenter randomized controlled trial of the clinical effectiveness of schema therapy for personality disorders. American Journal of Psychiatry, 171(3), 305-322.

Carter, J. D., McIntosh, V. V., Jordan, J., Porter, R. J., Frampton, C. M., \& Joyce, P. R. (2013). Psychotherapy for depression: A randomized clinical trial comparing schema therapy and cognitive behavior therapy. Journal of Affective Disorders, 151(2), 500-505.

Conklin, L. R., \& Strunk, D. R. (2015). A session-to-session examination of homework engagement in cognitive therapy for depression: Do patients experience immediate benefits? Behaviour Research and Therapy, 72, 56-62.

Flückiger, C., Del Re, A. C., Wampold, B. E., Symonds, D., \& Horvath, A. O. (2012). How central is the alliance in psychotherapy? A multilevel longitudinal meta-analysis. Journal of Counseling Psychology, 59(1), 10-17. https://doi.org/10.1037/a0025749.

Hayes, S. C., \& Hofmann, S. G. (2017). The third wave of cognitive behavioral therapy and the rise of process-based care. World Psychiatry, 16(3), 245-246. https://doi.org/10.1002/wps.20442.

Hayes-Skelton, S., \& Graham, J. (2013). Decentering as a common link among mindfulness, cognitive reappraisal, and social anxiety. Cognitive Psychotherapy, 41(3), 317-328. https://doi.org/10.1017/ S1352465812000902.

Hofman, S. G., Asnaani, A., Vonk, I. J., Sawyer, A. T., \& Fang, A. (2012). The efficacy of cognitive behavioral therapy: A review of meta-analyses. Cognitive Therapy and Research, 36(5), 427-440. https://doi.org/10.1007/s10608-012-9476-1.

Kennedy, H., Ball, K., \& Barlow, J. (2017). How does video interaction guidance contribute to infant and parental mental health and well-being? Clinical Child Psychology and Psychiatry, 22(3), 500-517. https://doi.org/10.1177/1359104517704026.

Leichsenring, F., \& Steinert, C. (2017). Is cognitive behavioral therapy the gold standard for psychotherapy? The need for plurality in treatment and research. JAMA, 318(14), 1323-1324.

Loewenthal, D. (2013). Talking Pictures Therapy in a school setting. Journal of Creativity in Mental Health, 8(1), 21-34. https://doi. org/10.1080/15401383.2013.763679.

Norton, P. J., \& Paulus, D. J. (2016). Toward a unified treatment for emotional disorders: Update on the science and practice. Behavior Therapy, 47(6), 854-868.

Orr, E. M. J., \& Moscovitch, D. A. (2014). Physical appearance anxiety impedes the therapeutic effects of video feedback in high socially anxious individuals. Behavioural and Cognitive Psychotherapy, 42(1), 92-104. https://doi.org/10.1017/S1352465812001038.

Renner, F., Arntz, A., Peeters, F. P., Lobbestael, J., \& Huibers, M. J. (2016). Schema therapy for chronic depression: Results of a multiple single case series. Journal of Behavior Therapy and Experimental Psychiatry, 51, 66-73.

Safran, J. D., \& Muran, J. C. (2000). Negotiating the therapeutic alliance. A relational treatment guide. New York: The Guilford Press.

Segal, Z. V., Anderson, A. K., Gulamani, T., Dinh Williams, L., Desormeau, P., Ferguson, A., et al. (2019). Practice of therapy acquired regulatory skills and depressive relapse/recurrence prophylaxis following cognitive therapy or mindfulness based cognitive therapy. Journal of Consulting and Clinical Psychology, 87(2), 161-170. https://doi.org/10.1037/ccp0000351.

Steele, M., Steele, H., Bate, J., Kanafo, H., Kinsey, M., Bonuck, K., et al. (2014). Looking from the outside in: The use of video in attachment-based interventions. Attachment and Human Development, 16(4), 402-415. https://doi.org/10.1080/14616 734.2014.912491.

Teasdale, J. D., \& Barnard, P. J. (1993). Affect, cognition, and change: Re-modelling depressive thought. Hove: Lawrence Erlbaum Associates.

Warnock-Parkes, E., Wild, J., Stott, R., Grey, N., Ehlers, A., \& Clark, D. M. (2017). Seeing is believing: Using video feedback in cognitive therapy for social anxiety disorder. Cognitive and Behavioral Practice, 24(2), 245-255.

Watts, S., Turnell, A., Kladnitski, N., Newby, J. M., \& Andrews, G. (2015). Treatment-as-usual (TAU) is anything but usual: A metaanalysis of CBT versus TAU for anxiety and depression. Journal of Affective Disorders, 175, 152-167.

Young, J. E. (1990). Schema-focused cognitive therapy for personality disorders: A schema focused approach. Sarasota, FL: Professional Resource Exchange.

Publisher's Note Springer Nature remains neutral with regard to jurisdictional claims in published maps and institutional affiliations. 